\title{
O trabalho autogestionário na economia solidária: afinal, o que recuperam e o que transformam as empresas recuperadas?
}

\section{The self-manager work on the solidary economy: after all, what recovers and what changes these recovered companies?}

\author{
Ana Beatriz Trindade de Melo \\ Doutoranda em Ciências Sociais (Pontifícia Universidade Católica de Minas Gerais/PUC-MG) \\ melo.anabeatriz@hotmail.com
}

\begin{abstract}
Resumo:
O avanço de iniciativas denominadas de Economia Solidária no Brasil revela o crescimento de um movimento social complexo e contraditório, que vem conquistando novos espaços na sociedade. As empresas recuperadas representam um capítulo à parte nesse cenário, dadas as particularidades de suas histórias, organização interna e atores sociais envolvidos. Tais iniciativas surgem em períodos de crise econômica como formas de atenuação do desemprego. Esse artigo tem por objetivo apresentar uma revisão bibliográfica sobre empresas recuperadas, com destaque para os desafios inerentes ao trabalho autogestionário. Ele se desenvolverá a partir de três momentos: 1) caracterização das novas configurações do trabalho no mundo e no Brasil e suas repercussões na emergência do movimento solidário; 2) análise de dados de contexto sobre o desenvolvimento da Economia Solidária no Brasil; 3) reflexão sobre a experiência de trabalho autogestionário em empresas recuperadas, com ênfase nas especificidades contextuais e organizacionais desses empreendimentos.
\end{abstract}

Palavras-chave: Trabalho. Economia Solidária. Autogestão. Cooperativas. Empresas Recuperadas.

\begin{abstract}
:
The advance of iniatives called Solidary Economy in Brazil reveals the increase of a complex and contradictory social movement, that has been earning a new space in society. The recovered companies represent a whole new chapter on this scenery, given the particularities of its stories, internal organization and the social actors envolved. Such iniatives rise in times of economical crisis, as ways of attenuation of unemployment. This article aims to present a bibliographic review over recovered companies, highlighting the challenges that are part of the self-manager work. It will be developed after 3 moments: 1) charachterization of the new configuration of the work worldwide and in Brazil, and its repercussion on the rising of the solidary movement; 2) analisys of context data about the Solidary Economy development in Brazil; 3) reflexion over the self-manager experience in recovered companies, focusing on the contextual and organizational specificities of those enterprises.
\end{abstract}

Keywords: Work. Solidary. Economy. Self-management. Cooperatives. Recovered Companies.

Originais recebidos em: 01/07/11

Aceito para publicação em: 11/09/11

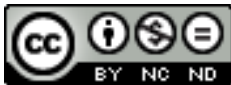

Este trabalho está licenciado sob uma Licença Creative Commons Atribuição-Uso NãoComercial-Vedada a criação de obras derivadas 3.0 Unported License 


\section{Introdução}

\section{As novas configurações do trabalho: precarização e informalidade}

Nas últimas décadas, ocorreram profundas transformações sociais, políticas, culturais e econômicas em âmbito mundial que culminaram na difusão e consolidação de um novo regime de acumulação capitalista marcado, por um lado, pelos processos de globalização, desterritorialização e financeirização do capital e, por outro, por significativas mudanças nas relações de trabalho e emprego. A partir desse novo regime, parcelas crescentes da população - em especial, os mais velhos e os mais jovens passaram a depender cada vez mais de atividades calcadas no trabalho precário, informal e terceirizado para sobreviver em um mercado sem fronteiras altamente excludente e competitivo.

Ao longo dos anos 90, concomitantemente aos processos de precarização/flexibilização das relações de trabalho, o desemprego atingia níveis alarmantes, sobretudo nos países em desenvolvimento. Surge, daí, um novo cenário caracterizado fundamentalmente por uma grande crise no que Castel (1995) denominou de "sociedade salarial", isto é, um regime social no qual a maioria das pessoas recebia não somente uma renda, mas, além disso, possuía um estatuto de reconhecimento, visibilidade e identidade pela via do trabalho.

A sociedade salarial, que representava uma ruptura em relação à precariedade de tempos anteriores, promoveu um novo regime de acumulação - regime fordista -, cujo desenvolvimento marcou, em especial os países centrais, da gloriosa década de 30 até os anos 70. Nesse contexto, o trabalho - em sua condição moderna de trabalho assalariado - convertia-se na matriz estruturante dos processos de integração social e no ponto de partida para um conjunto de direitos e garantias que protegiam o assalariado de diversos riscos sociais.

Para Castel, os dois pilares fundamentais sobre os quais a sociedade salarial se fundamentou foram, de um lado, o desenvolvimento econômico e, de outro, a consolidação do Estado de Bem Estar Social (Welfare State).

O desenvolvimento econômico se mostrou capaz de integrar o progresso social, entendido como finalidade comum entre diferentes grupos, ao aumento da produtividade (produção em massa), do consumo (consumo em massa) e da renda 
salarial. Nesse cenário, o trabalhador assalariado, a partir de seus modos de consumo, sua utilização do crédito e seu investimento em bens duráveis, passou a exercer um papel central no processo de crescimento econômico, articulando sua trajetória à projeção de um progresso indefinido, capaz de ultrapassar gerações.

O Estado de Bem Estar Social, por sua vez, se estabelecia como instância reguladora e garantidora de certo equilíbrio, de certa harmonia, embora precária, entre o econômico e o social, combinando ações que visavam tanto a promoção das condições necessárias a produção de riquezas, quanto o desenvolvimento de direitos e proteções relacionados ao trabalho As intervenções desse Estado se desdobravam, basicamente, em três direções: garantia de uma proteção social generalizada, controle efetivo das forças de mercado e mediação do compromisso estabelecido entre capital e trabalho.

A montagem desenvolvimento econômico - regulação estatal, difundida a partir da sociedade salarial, tinha por objetivo, sobretudo, assegurar uma condição de estabilidade, progresso e segurança, segundo a qual conquistas econômicas como o enriquecimento coletivo, o aumento da produtividade, o crescimento das remunerações relativas ao trabalho assalariado e a massificação do consumo se mesclavam a conquistas sociais, tal qual a realização de uma repartição mais igualitária de oportunidades, a consolidação do direito do trabalho, a extensão das proteções sociais, o maior acesso a propriedade e a moradia, entre outras. Nesse contexto, o déficit de integração, que havia caracterizado o início da sociedade industrial, parecia diluir-se na crença de um futuro tranqüilo e próspero.

Essa trajetória, segundo Castel, acabou sendo interrompida. De fato, no final dos anos 60, o sistema econômico mundial começava a apresentar os primeiros sinais de uma profunda e longa crise.

Nesse novo cenário, os alicerces que sustentavam a sociedade salarial - regime de acumulação fordista e Estado de Bem Estar Social - sofreram um processo de deterioração, esgotamento e mutação. Foi desencadeado, desde então, um movimento de enfraquecimento da condição social estável a que teve acesso, durante o período fordista, boa parte dos assalariados dos países industrializados, o que resultou em uma profunda degradação do equilíbrio já bastante precário vigente entre a esfera social e a esfera econômica.

A partir da degradação da sociedade salarial, consolidou-se um novo ambiente macroeconômico marcado pela hegemonia de políticas de corte neoliberal, a partir das quais os direitos e as proteções sociais dos trabalhadores assalariados passaram a ser 
sistematicamente atacados. Tais ataques eram, geralmente, "justificados" com base no diagnóstico neoliberal que classificava os direitos e as garantias sociais como obstáculos ao desenvolvimento econômico.

O fordismo começava a sofrer os primeiros influxos do toyotismo, um momento em que a própria estrutura da relação salarial fordista era fortemente questionada. Gestão em fluxo tenso, sistemas de produção just in time e Kanban, trabalhos sob encomenda, valorização de sistemas meritocráticos e intensificação das formas de subcontratação e terceirização da força de trabalho se tornavam os imperativos categóricos para a organização de empresas competitivas.

Nesse contexto, a figura emblemática do trabalhador típico da sociedade salarial, ou seja, o operário altamente especializado, protegido e regulamentado, que, em geral, era contratado por tempo indeterminado e, a partir de seu trabalho, tinha conquistado uma condição social estável, vem perdendo espaço para um novo tipo de trabalhador. O que fica evidenciado, atualmente, é a significativa expansão dos trabalhadores flexibilizados e precarizados, isto é, prestadores de serviços ou "colaboradores" desprovidos de direitos, sem estabilidade no emprego e, em muitos casos, sem vínculos empregatícios claramente estabelecidos.

Desenvolvem-se, nesse panorama, formas particulares de trabalho que abrangem uma série de situações heterogêneas e diversificadas: contratos de trabalho por tempo determinado, interinidade, trabalho de tempo parcial, serviços pontuais, "bicos", entre outras.

Vem se expandindo, desde então, um conjunto cada vez maior de "trabalhadores sem trabalho", os quais foram nomeados por Castel de "inúteis para o mundo", visto que vivem na sociedade sem verdadeiramente lhe pertencer. Esses trabalhadores sem trabalho ocupam uma posição de supranumerários, visto que vagam continuamente de ocupação em ocupação, flutuando numa espécie de no man's land social, sem nenhum tipo de perspectiva em relação à conquista de lugares que lhes garantam algum status no sentido da utilidade social e do reconhecimento público. A precariedade e a instabilidade desse modo de estar no mundo impõem estratégias de sobrevivência fundadas quase que exclusivamente no presente, em que se vive apenas o dia a dia.

$\mathrm{O}$ trabalho assume, portanto, uma nova morfologia, uma nova polissemia, cujo traço mais visível reside em seu caráter multifacetado, conseqüência das profundas mudanças que afetaram o mundo produtivo do capital nas últimas décadas. Essa nova morfologia envolve desde o operariado industrial e rural clássicos, que vêm se 
reduzindo, até os assalariados do setor de serviços e o enorme contingente de trabalhadores terceirizados, subcontratados e temporários, em processo de expansão.

Segundo Leite (2009), os processos de globalização e reestruturação produtiva representam muito mais do que uma acomodação ou adequação do mercado financeiro e produtivo ao caráter flexível das novas tecnologias: eles revelam o resultado de decisões políticas de setores sociais que, diante da nova correlação de força estabelecida entre capital e trabalho, resolveram não apenas romper com o pacto anterior, mas destruir o conjunto das institucionalidades que sustentavam a chamada sociedade salarial.

É a partir desse quadro que se deve compreender a crise das políticas keynesianas do Estado de Bem Estar Social, as transformações no caráter do Estado e o conseguinte desenvolvimento de políticas neoliberais, além das tendências de terceirização e flexibilização do emprego e do trabalho.

No caso do Brasil, em que a renda é historicamente concentrada, a sociedade salarial não chegou a se estabelecer em seu sentido pleno e a consolidação do Estado de Bem Estar Social sempre foi muito questionada, essa crise do trabalho apresenta contornos ainda mais dramáticos.

A década de 90 foi marcada em nosso país tanto por um esgotamento do dinamismo da indústria nacional após a abertura passiva do mercado interno às importações quanto pelo abandono do papel ativo do Estado a partir da afirmação de uma política de privatizações e terceirizações. Tais processos resultaram no desenvolvimento de novos padrões produtivos e distributivos "fundamentados em uma maior especialização econômica, ditada exclusivamente pelo mercado e circunscrita aos grandes grupos econômicos nacionais e transnacionais aqui localizados" (MATTOSO; POCHMANN, 1998, p. 224).

A abertura indiscriminada ao comércio globalizado e a desregulamentação financeira levaram, por um lado, a fragilização e quebra de diversos bancos e empresas impossibilitados de se adaptarem ao novo ambiente competitivo e, por outro, a estagnação das exportações acompanhada por um aumento sem precedentes das importações, o que desencadeou uma verdadeira invasão de produtos importados, particularmente os de origem chinesa. As indústrias têxtil, calçadista, automobilística e de eletrodomésticos destacam-se entre os setores mais atingidos por esses processos. 
Com efeito, assistiu-se, durante a década de 90, a um movimento de expansão do desemprego e das ocupações informais ${ }^{1}$ concomitantemente à diminuição significativa dos trabalhos formais. Ocorreu nesse período uma redução da importância relativa ao núcleo sólido do trabalho - composto por contingentes de ocupados com vínculos empregatícios formalizados e alguma proteção social - e, ao mesmo tempo, sua reconfiguração conforme uma economia desregulamentada, à mercê dos “humores' dos agentes do mercado financeiro.

Contudo, vale chamar a atenção para o fato de que, ao longo da última década, os dados relativos ao mercado de trabalho vêm apontando para uma significativa recuperação do emprego formal, em função, sobretudo, da adoção de medidas institucionais orientadas para o cumprimento da legislação trabalhista bem como para a contenção das formas precárias de trabalho, a partir de ações do Ministério Público do Trabalho e da Justiça do Trabalho. Observa-se, nesse contexto, uma redução contínua dos índices de desemprego ${ }^{2}$, do trabalho por conta própria, do trabalho sem remuneração e do trabalho precário.

De acordo com Leite, esses dados revelam, por um lado, que a precarização e a informalização não são tendências inexoráveis, mas que podem ser controladas através de políticas voltadas para o crescimento da economia como um todo (em particular do setor industrial), além de medidas específicas contra a informalidade e a precarização. Por outro lado, eles ainda apontam para um quadro de forte desestruturação do mercado de trabalho no Brasil, em que o setor desorganizado abrange cerca de $40 \%$ da população economicamente ativa (PEA).

Diante desse contexto, deve-se perguntar: o que poderia ser feito para enfrentar e minimizar os graves impactos sócioeconômicos produzidos pela informalidade e pelo desemprego? Ou ainda: qual será o futuro dos excluídos do mercado formal de trabalho que, por essa condição, não são sequer reconhecidos como cidadãos?

\footnotetext{
${ }^{1}$ Segundo publicação relativa a Pesquisa Mensal de Emprego (PME) apresentada em janeiro de 2000 pelo Instituto Brasileiro de Geografia e Estatística (IBGE), compreendendo as seis principais regiões metropolitanas do País (Recife, Salvador, Belo Horizonte, Rio de Janeiro, São Paulo e Porto Alegre), a taxa média de desemprego aberto no ano de 1999 foi de 7,6\%, a maior observada desde 1983. Já o percentual de empregados sem careteira assinada no mesmo ano chegou a $26,4 \%$ e o dos trabalhadores por conta própria foi de $23,6 \%$, totalizando $50 \%$ da população economicamente ativa (PEA) dedicada a atividades ditas "informais".

${ }^{2}$ De acordo com publicação relativa à Pesquisa Mensal de Emprego (PME) apresentada em janeiro de 2011 pelo Instituto Brasileiro de Geografia e Estatística (IBGE), a taxa média de desocupação (tal índice foi adotado a partir de uma revisão da pesquisa em 2002), no ano de 2010 foi de $6,7 \%$, a menor registrada desde o início da série da pesquisa. Já o nível de informalidade médio foi de $36,9 \%$ da população economicamente ativa revelando uma diminuição contínua em relação aos anos anteriores.
} 


\section{A Economia Solidária no Brasil: dados da realidade}

Uma possível resposta pode ser encontrada no conjunto diversificado de idéias e experiências reunidas sob a denominação de Economia Solidária.

De acordo com Singer e Souza (2003), a Economia Solidária se desenvolveu no Brasil de forma esparsa nos anos 80, tomando impulso a partir da segunda metade da década de 90. Nesse período, o desemprego estrutural, a informalidade e a precarização das relações de trabalho atingiam patamares alarmantes, levando a consolidação de um crescente exército pós-industrial de reserva, formado por trabalhadores desprotegidos pelo Estado e excluídos do mercado.

A Economia Solidária se difundiu inicialmente como resposta/reação a esse quadro de profunda crise do trabalho assalariado. Pessoas que perderam seus empregos e não conseguiam se reinserir no mercado, além daquelas que sempre viveram na informalidade, passaram a desenvolver um conjunto diversificado de atividades voltadas para geração de trabalho e renda, com base na autogestão e na participação coletiva. Com o passar dos anos, o movimento solidário ganhou escala e representatividade em nível local, regional e nacional, firmando sua identidade a partir de características e demandas específicas. Centenas de iniciativas que tendiam a ficar isoladas e, por isso debilitadas, se expandiram, estabelecendo intercâmbios e recebendo assessoria de instituições das mais diversas origens (sindicatos, universidades, igrejas, entre outras).

No que diz respeito às suas influências históricas, Singer e Souza sustentam que a Economia Solidária remete aos princípios e às experiências cooperativistas ${ }^{3}$ que se consolidaram na Inglaterra após o século XVIII, como resultado de lutas operárias contra os efeitos excludentes da Revolução Industrial. Nesse mesmo período, ganhavam notoriedade no cenário europeu conjurações e críticas de pensadores conhecidos como socialistas utópicos - Charles Fourier, Claude Saint-Simon, Robert Owen e PierreJoseph Proudhon - que, apoiando-se na filosofia de Rousseau, formulavam modelos

\footnotetext{
${ }^{3}$ Dentre essas experiências, vale destacar a cooperativa dos Pioneiros Equitativos de Rochdale, criada em 1844 em Manchester. Foi a primeira iniciativa a desenvolver uma carta de princípios cooperativistas. Tais princípios, ao longo da história, passaram por inúmeras reformulações, sendo a última concluída em 1995, a partir do XXI Congresso Mundial promovido pela Aliança Cooperativa Internacional (ACI), órgão de representação mundial do movimento cooperativista. No contexto atual, os princípios cooperativistas se constituem em: adesão livre e voluntária dos cooperados; gestão democrática; participação econômica; autonomia e independência; educação, treinamento e informação; preocupação com a comunidade.
} 
alternativos, calcados em especulações e empirismos, para a organização de uma sociedade mais livre e justa. ${ }^{4}$

No cenário brasileiro, entre os antecessores da Economia Solidária, vale chamar a atenção para importantes ações ligadas ao movimento popular urbano e rural: a) o movimento sindical, em particular o denominado autêntico ou combativo, tendo a Central única dos Trabalhadores (CUT) à frente; b) intervenções organizadas junto a parcelas mais vulneráveis da população, principalmente nos centros urbanos, em que ocorreram articulações entre grupos progressistas ligados à Igreja Católica (em especial, os influenciados pela Teologia da Libertação), setores do movimento estudantil e partidos de esquerda, a exemplos das Comunidades Eclesiais de Base (CEBs), das Pastorais Sociais, das Sociedades Amigas de Bairros (SABs) e de ações políticas como o Movimento contra a Carestia e o Custo de Vida; c) o cooperativismo popular, difundindo iniciativas comprometidas com a democracia na produção e na comercialização, opondo-se ao perfil empresarial do cooperativismo tradicional ou oficial ligado à Organização das Cooperativas Brasileiras (OCB); d) o Movimento dos Trabalhadores Rurais Sem Terra (MST) que, com o objetivo de viabilizar economicamente seus assentamentos, incentivou a organização de diferentes tipos de cooperativas, contando com o apoio de uma escola própria de formação de técnicos em cooperativismo.

Para Gaiger (2004), os empreendimentos econômicos solidários (EES), no que resguarda a sua organização e desenvolvimento, se caracterizam pela adoção de sete princípios norteadores: a autogestão, a cooperação, o igualitarismo, a democracia participativa, a auto-sustentação, a responsabilidade social e o desenvolvimento sustentável. A esses empreendimentos correspondem experiências heterogêneas, incluindo iniciativas de agricultura familiar, assentamentos de terra, associações, cooperativas, empresas recuperadas a partir de preceitos autogestionários, bancos populares, redes de comércio justo, entre outras.

As atividades desenvolvidas pelos EES são bastante diversificadas: estas podem compreender projetos de confecção de roupas, artesanato, coleta e reciclagem de lixo, produção de alimentos, serviços gerais, entre outras, as quais recebem freqüentemente apoio tanto de organizações da sociedade civil quanto do poder público, a partir do

\footnotetext{
${ }^{4}$ Ver "Novos movimentos sociais e economia solidária: uma breve cartografia da autogestão como processo de subjetivação" (MELO, 2007).
} 
desenvolvimento e implementação de políticas públicas em âmbito municipal, estadual e nacional.

De acordo com a última edição do Atlas da Economia Solidária no Brasil, publicada, em 2008, pela Secretaria Nacional de Economia Solidária (SENAES), órgão vinculado ao Ministério do Trabalho e Emprego (MTE), em conjunto com o Fórum Brasileiro de Economia Solidária (FBES), existem atualmente 1.687 .496 pessoas trabalhando de forma direta em 21.859 empreendimentos solidários no Brasil.

Os números do Atlas revelam o crescimento de um movimento social extremamente complexo e conflitante, portador, a um só tempo, de inúmeros riscos e possibilidades, que, nos últimos anos, vem conquistando novos espaços na sociedade institucionais ou não -, chamando a atenção de vários estudiosos e pesquisadores. Se for grande a diversidade dessas novas formas de geração de trabalho e renda, também parecem ser diversos os significados a elas atribuídos por seus críticos e defensores.

De acordo com Leite (2008), não existe qualquer tipo de unidade em relação ao conceito de Economia Solidária. O que se observa atualmente é o desenrolar de uma intensa e calorosa discussão sobre o assunto, com opiniões e teorias significativamente diferentes e discordantes, em muitos casos, carregadas de conteúdos ideológicos.

A partir desses intensos debates, ganham centralidade questões relevantes que podem ser apresentadas da seguinte forma: Em que medida tais experiências podem ser compreendidas como capazes de promover uma transformação social, emergindo como germes de uma nova sociedade "não capitalista"? Ou seriam elas tão-somente novas formas de informalidade e precarização do trabalho, resultantes da atual crise do capitalismo? Até que ponto representariam simples rações ao desemprego, sendo rapidamente absorvidas a partir do crescimento do mercado formal? Em que medida podem ser vistas como experiências contemporâneas de organização e mobilização dos trabalhadores baseadas numa idéia renovada de democracia participativa, a partir da qual novas relações sociais e políticas são construídas, auto-estimas são valorizadas e destinos comuns são traçados?

Longe de qualquer pretensão conclusiva, vale chamar a atenção para duas importantes considerações que, de certa forma, atravessam tal discussão.

A primeira delas diz respeito ao fato de que é preciso estar atento as "falsas cooperativas", ou, em outras palavras, cooperativas de fachada desenvolvidas a partir de brechas jurídicas, com os objetivos de burlar as leis trabalhistas e camuflar relações empregatícias em nome de políticas de gestão voltadas prioritariamente para a redução 
de custos e maximização dos lucros. Essas experiências correspondem a formas "selvagens" de precarização e terceirização do trabalho, em que os princípios de autogestão, igualitarismo e solidariedade definitivamente não têm vez. Não possuem, portanto, nenhum tipo de relação ideológica ou organizacional com o movimento de Economia Solidária.

Já a segunda consideração refere-se ao seguinte fato: as iniciativas solidárias, embora unidas teoricamente por critérios e princípios, apresentam uma série de especificidades no que diz respeito à sua história, organização, trajetória dos atores sociais envolvidos, inserção no mercado, articulações com entidades de apoio e poder público, entre outros fatores. Nesse sentido, cooperativas, associações, empresas recuperadas, experiências de agricultura familiar e bancos populares - só pra citar alguns, entre os diversos empreendimentos solidários - designam realidades bem distintas que devem ser ressaltadas e analisadas com profundidade.

Nesse contexto, as empresas recuperadas, embora não tenham grande representatividade quantitativa em relação às demais iniciativas solidárias ${ }^{5}$, despontam como um capítulo à parte, nem sempre contemplado pela grande maioria das pesquisas dedicadas à Economia Solidária.

\section{Empresas recuperadas: dilemas e desafios}

Segundo Lima (2007), as empresas recuperadas ganharam visibilidade no Brasil a partir do final dos anos 80 . O ponto de partida desse processo situa-se em movimentos pontuais de recuperação de fábricas falidas, como fruto da organização de trabalhadores para manter seus empregos. Tais iniciativas eram em geral apoiadas e organizadas por órgãos de fomento internacionais, caso da Interamerican Foundation ${ }^{6}$ que financiou inúmeros projetos de cooperativas por todo o país, ou mesmo da Igreja Católica, através da participação de intelectuais, como foi o caso da Unilabor, fábrica de móveis localizada em São Paulo, cujas atividades tinham por base os princípios do grupo católico francês Economia e Humanismo. ${ }^{7}$

\footnotetext{
${ }^{5}$ Segundo o Atlas da Economia Solidária no Brasil, no que se refere ao tipo de organização, a maior proporção desses empreendimentos se refere às associações $(51,8 \%)$, seguidas pelos grupos informais $(36,5 \%)$, pelas cooperativas $(9,7 \%)$, por outras formas $(1,4 \%)$ e pelos que não informaram $(0,6 \%)$. ${ }^{6}$ Agência independente do governo dos Estados Unidos para cooperação internacional com objetivos de apoiar e financiar projetos de desenvolvimento local na América Latina e Caribe.

${ }^{7}$ Grupo criado na França, em 1941, pelo padre dominicano Louis-Joseph Lebret que propunha o envolvimento da Igreja em questões econômicas a fim de criar soluções para as desigualdades sociais.
} 
Com o advento dos anos 90, observou-se um crescimento significativo do número de fábricas em situação falimentar no Brasil, o que levou empresários e trabalhadores a discutir, juntos ou não, propostas de recuperação de unidades fabris em risco que, posteriormente, acabaram sendo transformadas em pequenos empreendimentos autogestionários.

Os sindicatos tiveram um papel estratégico na formação e organização dessas iniciativas, que ficaram conhecidas na literatura especializada como empresas recuperadas. Nesse sentido, vale destacar os trabalhos de incubação e orientação desenvolvidos pela Associação Nacional dos Trabalhadores e Empresas de Autogestão e Participação Acionária (ANTEAG), pela Agência Nacional de Desenvolvimento Solidário (ADS) e pela Central de Cooperativas e Empreendimentos Solidários (UNISOL), ambas ligadas ao movimento sindical.

As empresas recuperadas, segundo Lima, mantêm o estatuto jurídico e econômico de propriedade privada, trocando serviços e produtos com outros agentes econômicos. Assim sendo, estão sujeitas às flutuações do mercado, com suas crises e retomadas.

Tal necessidade de adaptação a parâmetros competitivos determinados pelas demais unidades econômicas, de acordo com Dal Ri e Vieitez (2001), acaba por afetar vários aspectos do cotidiano das empresas recuperadas. Entre esses aspectos, convém destacar os relacionados diretamente à organização da produção, tal qual a adoção de novas tecnologias, o nível da qualidade dos produtos, o ritmo, o controle e a disciplina no trabalho, entre outros.

As empresas recuperadas procuram observar os princípios cooperativistas: nelas, a propriedade está atrelada a um coletivo formado por associados, que atuam, ao mesmo tempo, como trabalhadores e gestores. Ao ingressar no empreendimento, cada associado deve adquirir uma quantidade variável de cotas-partes da empresa. Contudo, "nenhum associado ou grupo de associados pode possuir um número de cotas suficiente para deter o controle sobre a empresa” (DAL RI; VIEITEZ, 2001, p. 20).

Nesse contexto, a autogestão desponta como cerne da proposta cooperativista, se consolidando como um atributo marcante das empresas recuperadas.

Ainda não há uma definição precisa e consensual sobre o termo autogestão. Todavia, vale chamar a atenção para alguns aspectos gerais que a caracterizam, segundo Gaiger (2003). São eles: a) propriedade coletiva dos meios de produção; sendo vedada a apropriação individual ou alienação particular; b) o controle do empreendimento e o 
poder de decisão pertencem aos trabalhadores, em regime de paridade de direitos; c) a gestão do empreendimento é realizada pela comunidade de trabalho que organiza o processo produtivo, opera as estratégias planejadas e dispõe sobre o destino dos rendimentos.

Para Gaiger, as práticas autogestionárias dão aos empreendimentos uma condição singular, pois modificam o princípio e a finalidade da extração do trabalho excedente. Nesse sentido, a autogestão designaria um modo de produção específico, a partir do qual é realizada a reconciliação entre o trabalhador, os meios produtivos que ele detém e utiliza e os resultados de seu trabalho.

No Brasil, o ressurgimento da autogestão como princípio norteador da Economia Solidária, segundo Albuquerque (2003), apresenta, por um lado, uma conotação fortemente econômica, relacionada à criação de um sistema gerencial capaz de salvar empreendimentos falidos, combatendo o desemprego em massa e, por outro, uma significação política relativa a um "ideal utópico de transformação e mudança social" (ALBUQUERQUE, 2003, p. 22).

Nos últimos anos, por circunstâncias diversas como a falência generalizada de fábricas de um mesmo setor e/ou por razões ideológicas articuladas em especial às expectativas pelo desenvolvimento de formas de trabalho mais democráticas e participativas capazes de propiciar maior autonomia a um coletivo, muitos trabalhadores buscam assumir o lugar do capital na gerência das empresas recuperadas. A partir dessas iniciativas, passa-se teoricamente de num primeiro momento em que predominavam relações de poder verticais entre capital e trabalho para um segundo momento no qual despontam relações horizontais e igualitárias entre trabalhadores.

A esse respeito, vale questionar como seriam tais relações de poder na prática e até que ponto esses trabalhadores, de fato, conseguiriam assumir tais espaços. A autogestão designaria um instrumento vital para eles? Haveria por trás dela, para além de uma conotação econômica, um significado político ${ }^{8}$

\footnotetext{
${ }^{8}$ Tais questões fazem parte da tese de doutorado provisoriamente intitulada de "Trabalho, autogestão e economia solidária: estudo de empresas recuperadas na Região Metropolitana de Belo Horizonte", que está sendo desenvolvida no Programa de Pós-Graduação em Ciências Sociais da Pontifícia Universidade Católica de Minas Gerais.
} 


\section{Considerações finais}

As teorias e práticas associadas à Economia Solidária são caracterizadas por uma profunda lacuna. Observa-se, nesse sentido, uma grande distância entre o desejável e o factível.

As experiências concretas não têm alimentado grandes esperanças, principalmente no que diz respeito a seu potencial de transformação e de reforma social: estas têm enfrentado muitos obstáculos para se afirmar e competir no mercado, seja pelo enfraquecimento dos princípios cooperativistas em momentos de ascensão econômica, seja por dificuldades em ganhar escala, seja pela falta de investimentos e apoio do poder público e da sociedade civil, seja pelos inúmeros problemas inerentes à comercialização e ao consumo dos produtos, seja pela baixa qualidade e alto preço das mercadorias, seja pelas dificuldades de acesso a créditos e financiamentos, seja pelos intensos conflitos e embates internos desencadeados em um cotidiano de trabalho autogestionário, entre outros fatores.

Contudo, é imprescindível destacar que essa dura realidade não invalida nem atenua a importância dos ganhos sociopolíticos que são enfatizados em inúmeras pesquisas sobre Economia Solidária a partir de conceitos como "cidadania", "identidades coletivas", "novas sociabilidades", "capital social", "nova cultura de trabalho", "autonomia", entre outros. Diversos estudos, de fato, dão visibilidade a relatos de trabalhadores, em que esses ganhos aparecem como centrais. Assim, o fato de um empreendimento solidário ser fruto de uma necessidade material imediata - sua finalidade primeira é econômica enquanto iniciativa de geração de trabalho e renda não significa necessariamente que ele não seja portador de outras potencialidades.

Trata-se, assim, de uma realidade um tanto complexa e, sobretudo, contraditória. Muitos trabalhadores, por um lado, abandonam os empreendimentos solidários na primeira oportunidade que lhes é oferecida pelo mercado formal e atribuem sua decisão, em geral, a baixa renda ${ }^{9}$ obtida a partir do trabalho cooperativo e a sensação de instabilidade (ausência de proteção e direitos relacionados a carteira assinada). Outros, por sua vez, optam conscientemente em continuar trabalhando em iniciativas solidárias

\footnotetext{
${ }^{9}$ Segundo o Atlas da Economia Solidária no Brasil, no que diz respeito às classes de faturamento mensal dos empreendimentos econômicos solidários, cerca de 30\% afirmaram não ter faturamento mensal, quase $25 \%$ disseram faturar entre R\$ $1.001,00$ e R $\$ 5.000,00$, seguidos por cerca de $15 \%$ que ganham até R\$ $1.000,00$. Nesse sentido, vale destacar que a grande maioria das iniciativas (cerca de 70\%) encontra-se na margem entre os que declararam não ter faturamento aos com faturamento até R\$ 5.000,00.
} 
e justificam com freqüência suas decisões com base nos ganhos sociopolíticos (constituição de novos suportes relacionais, aumento de auto-estima, entre outros). Talvez esteja justamente aí - nesses ganhos - um dos segredos da permanência e do desenvolvimento da Economia Solidária no cenário nacional por mais de duas décadas.

\section{Referências Bibliográficas}

ALBUQUERQUE, Paulo P. Autogestão. In: CATTANI, Antônio (Org.). A outra economia. Porto Alegre: Veraz, 2003.

ANTUNES, R. Adeus ao trabalho? São Paulo: Cortez, 1997.

BERTUCCI, Jonas de Oliveira, FERREIRA, Cândido Guerra. A economia popular solidária em Belo Horizonte. Belo Horizonte: CEDEPLAR/FACEUFMG, 2005.

BORGES, Ângela. Mercado de trabalho: mais de uma década de precarização. In: DRUCK, G.; FRANCO, T. (Orgs). A perda da razão social do trabalho. São Paulo: Boitempo, 2007

CASTEL R. As metamorfoses da questão social. Petrópolis: Vozes, 1995.

CATTANI, Antônio (Org). A outra economia. Porto Alegre: Veraz, 2003.

DAL RI, Neusa Maria; VIEITEZ, Candido Giraldez. Trabalho associado: cooperativas e empresas de autogestão. Rio de Janeiro: DP\&A, 2001.

DRUCK, G.; FRANCO, T. (Orgs). A perda da razão social do trabalho. São Paulo: Boitempo, 2007.

GAIGER, Luiz Inácio. A economia solidária diante do modo de produção capitalista. In: Caderno CRH, Salvador, n. 39, p. 181-211, jul-dez. 2003.

Sentidos e experiências da economia solidária no Brasil. Porto Alegre:

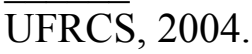

INSTITUTO BRASILEIRO DE GEOGRAFIA E ESTATÍSTICA. Pesquisa Mensal de Emprego. Brasília: IBGE, 2011. Disponível em < 
http://www.ibge.gov.br/home/estatistica/indicadores/trabalhoerendimento/pme nova/de $\underline{\text { fault.shtm }>}$

LEITE, Márcia de Paula. O trabalho e suas reconfigurações: conceitos e realidades. In: ARAÚJO, Ângela Maria Carneiro; LEITE, Márcia de Paula (Orgs). O trabalho reconfigurado: ensaios sobre Brasil e México. São Paulo: Annablume, 2009.

LEITE, Márcia de Paula. A economia solidária e o trabalho associativo, In: Revista Brasileira de Ciências Sociais, vol. 24, n. 69, p. 31-51, dez. 2008.

LIMA, Jacob Carlos. Trabalho em cooperativas: dilemas e perspectivas. In: DRUCK, G.; FRANCO, T. (Orgs). A perda da razão social do trabalho. São Paulo: Boitempo, 2007.

LIMA, Jacob Carlos; SOARES, Maria José. Trabalho flexível e o novo informal. In: Caderno do CRH, Salvador, v. 37, p. 163-178, 2002.

LIMA, Jacob Carlos. Paradoxos do trabalho associado. In: Tempo Social, São Paulo, vol. 21, p. 113-132, 2009.

. Reestruturação industrial, desemprego e autogestão: as cooperativas do Vale dos Sinos. In: Sociologias, Porto Alegre, ano 10, vol. 19, p. 212-249, jan.-jun. 2008.

MATTOSO, Jorge; POCHMANN, Márcio. Mudanças estruturais e trabalho no Brasil. In: Economia e Sociedade, Campinas, vol. 10, p.213-243, jun. 1998.

MELO, Ana Beatriz Trindade de. Novos movimentos sociais e economia solidária: uma breve cartografia da autogestão como processo de subjetivação. 2007, $151 \mathrm{f}$.

Dissertação (Mestrado) - Pontifícia Universidade Católica de Minas Gerais, Programa de Pós-Graduação em Psicologia, Belo Horizonte.

MINISTÉRIO DO TRABALHO E EMPREGO; SECRETARIA NACIONAL DE ECONOMIA SOLIDÁRIA. Atlas da Economia Solidária no Brasil. Brasília: SENAES, 2008. Disponível em: $<\underline{\text { http://www.mte.gov.br/sistemas/atlases }>}$

NEVES, Magda de Almeida. As transformações no mundo do trabalho: crise e debates. Revista TRT, Belo Horizonte, n. 27, p. 25-33, jul-dez. 1997. 
NEVES, Magda de Almeida. Dinâmicas de trabalho na cidade: informalidade e autogestão. In: ARAÚJO, Ângela Maria Carneiro; LEITE, Márcia de Paula (Orgs). $O$ trabalho reconfigurado: ensaios sobre Brasil e México. São Paulo: Annablume, 2009.

SINGER, Paul; SOUZA, André. A Economia Solidária no Brasil. São Paulo: Contexto, 2003. 